6 OPEN ACCESS

- Additional material is published online only. To view please visit the journal online (http://dx.doi.org/10.1136/ tobaccocontrol-2018-054333).

${ }^{1}$ Department of Pediatrics, Division of Adolescent Medicine, Stanford University School of Medicine, Palo Alto, California, USA

${ }^{2}$ School of Public Health, Georgia State University, Atlanta, Georgia, USA ${ }^{3}$ Center for Tobacco Control Research and Education, University of California, San Francisco, California, USA ${ }^{4}$ Division of Oral Epidemiology and Dental Public Health, University of California, San Francisco, California, USA ${ }^{5}$ General Internal Medicine/ Zuckerberg San Francisco General Hospital, University of California, San Francisco, California, USA

\section{Correspondence to} Dr Bonnie Halpern-Felsher, Department of Pediatrics, Division of Adolescent Medicine, Stanford University School of Medicine, Palo Alto, CA 94402, USA;

bonnie.halpernfelsher@ stanford.edu

Received 21 February 2018 Revised 21 June 2018 Accepted 22 June 2018 Published Online First 29 August 2018

\title{
IQOS labelling will mislead consumers
}

\author{
Karma McKelvey, ${ }^{1}$ Lucy Popova, ${ }^{2}$ Minji Kim, ${ }^{3}$ Lauren Kass Lempert, ${ }^{3}$ \\ Benjamin W Chaffee, ${ }^{3,4}$ Maya Vijayaraghavan,, 3,5 Pamela Ling, ${ }^{3}$ \\ Bonnie Halpern-Felsher ${ }^{1}$
}

\section{ABSTRACT \\ Background Philip Morris International (PMI)}

continually expands and diversifies their nicotine product portfolio, which includes IQOS, a heated tobacco product. In December 2016, PMI filed a modified risk tobacco product (MRTP) application with the US Food and Drug Administration (FDA), seeking authorisation to market IQOS in USA with three claims of reduced harm: 'switching completely from conventional cigarettes to the IQOS system...' (1) 'can reduce the risks of tobaccorelated diseases;' (2) 'significantly reduce[s] your body's exposure to harmful or potentially harmful chemicals;' and (3) 'presents less risk of harm than continuing to smoke cigarettes.' Consumers may misunderstand what is meant by 'switching completely'.

Methods We critically reviewed study reports submitted to FDA by PMI in support of proposed marketing claims in its MRTP application for IQOS and focused on the statement that switching completely to IQOS reduces risk.

Results We found deficiencies with evidence provided by PMI supporting their assertions that: current smokers will understand what is meant by the phrase 'switching completely'; the proposed claims will not decrease smokers' intentions to quit; and IQOS users will in fact 'switch completely' from smoking cigarettes to using IQOS. The studies and measurement instruments employed by PMI suffer from design flaws and their reporting of associated findings is misleading.

Conclusion Consumers will not understand the condition of the claims - that they must quit using cigarettes completely to achieve the inferred health benefits of IQOS. Rather, they are likely to misunderstand the unsupported claims of reduced risks to mean IQOS are harm-free.

\section{INTRODUCTION}

As tobacco companies increasingly expand and diversify their nicotine product portfolio, ${ }^{1}$ new heated tobacco products (HTPs), also known as heat-not-burn products, that heat modified cigarettes to produce an aerosol for inhalation have been introduced worldwide, ${ }^{2-4}$ including Philip Morris International's (PMI's) IQOS. ${ }^{25}$ As of February 2018, PMI's marketing in several countries claims that because IQOS heats tobacco sticks, not burns them, it poses lower risks than regular combustible cigarettes. These claims have already been made explicitly on PMI's website and in interviews with the media. ${ }^{67}$ In December 2016, PMI filed a modified risk tobacco product (MRTP) application with the US Food and Drug Administration (FDA), seeking authorisation to market IQOS in USA with three claims, each addressing a particular section of FDA regulation for MRTP applications (see table 1) - two focused on claims of reduced risk, and one focused on the claim of reduced exposure. These claims are provided to participants by PMI in its studies as 'Available Evidence to Date' to discern consumer perceptions of the proposed claims in light of 'warnings' also provided by PMI.

Tobacco companies' history of manipulating scientific studies and interpretation of findings makes it imperative that independent scientists examine the study designs, underlying data and conclusions from all tobacco industry-drive studies, including those involving IQOS and MRTP claims. ${ }^{8}$ It is also necessary to bring in research from other fields or with other tobacco products to help inform the regulatory agencies on the potential effects of the new tobacco products and proposed marketing claims. For example, to help inform its decision regarding IQOS, FDA would be well served to consider the recent and well-documented experience with e-cigarettes. In particular, exposure to electronic cigarette ('e-cigarette') advertisements has been shown to cause increases in smoking urges among adult former and current smokers, reduce adolescent never-smokers' perceived risks of regular cigarettes, and to be associated with increased odds of e-cigarette and cigarette use in both cross-sectional and longitudinal studies. ${ }^{910}$

In USA, FDA may issue a risk modification order permitting an MRTP to be commercially marketed only if the applicant has demonstrated that the product, as it is actually used by consumers, will: (1) Significantly reduce harm and the risk of tobacco-related disease to individual tobacco users. (2) Benefit the health of the population as a whole, taking into account both users of tobacco products and persons who do not currently use tobacco (Tobacco Control Act section 911(g)(1)). If scientific evidence is not currently available to meet these standards, FDA may issue an exposure modification order permitting the marketing of an MRTP that claims to reduce or eliminate exposure to a substance if reduced morbidity or mortality is likely to be demonstrated in future studies and it would 'promote the public health' (Tobacco Control Act section 911(g)(2)). The labelling claims made for MRTPs seeking an exposure modification order must be limited to an explicit or implicit representation that: (1) The tobacco product or its smoke does not contain a substance. (2) The product or its smoke contains a reduced level of a substance. (3) The product presents reduced exposure to a substance in tobacco smoke (Tobacco Control Act section 911(g)(2)(A)(ii)). (See supplementary appendix A for details). 
Table 1 Summary of the text provided to participants in Phillip Morris International's (PMI's) studies conducted to evaluate consumer understanding and associated behavioural effects of proposed claims for the IQOS heated tobacco product

\begin{tabular}{|c|c|c|}
\hline Study: THS-PBA-05-RRC-US ${ }^{17}(n=2255)$ & Study: THS-PBA-05-RRC2-US ${ }^{18}(n=2247)$ & Study: THS-PBA-05-REC-US ${ }^{19}(n=2272)$ \\
\hline $\begin{array}{l}\text { Available evidence to date: claim } 1^{*} \\
\text { The iQOS system heats tobacco but does not burn it. } \\
\text { This significantly reduces the production of harmful } \\
\text { and potentially harmful chemicals. } \\
\text { Scientific studies have shown that switching } \\
\text { completely from conventional cigarettes to the } \\
\text { iQOS system can reduce the risks of tobacco-related } \\
\text { diseases. }\end{array}$ & $\begin{array}{l}\text { Available evidence to date: claim } 2^{*} \\
\text { Switching completely to iQOS presents less risk of } \\
\text { harm than continuing to smoke cigarettes. }\end{array}$ & $\begin{array}{l}\text { Available evidence to date: claim } 3^{*} \\
\text { The iQOS system heats tobacco but does not burn it. } \\
\text { This significantly reduces the production of harmful } \\
\text { and potentially harmful chemicals. } \\
\text { Scientific studies have shown that switching } \\
\text { completely from cigarettes to the iQOS system } \\
\text { significantly reduces your body's exposure to harmful } \\
\text { or potentially harmful chemicals. }\end{array}$ \\
\hline $\begin{array}{l}\text { Important warning: } \dagger \\
\text { Reduced risk does not mean no risk. The best way } \\
\text { to reduce your risk of tobacco-related diseases is to } \\
\text { completely quit tobacco use. } \\
\text { HeatSticks contain nicotine, which is addictive. } \\
\text { Using the iQOS system can harm your health. }\end{array}$ & $\begin{array}{l}\text { Important warning: } \dagger \\
\text { Less risk of harm does not mean no risk of harm. } \\
\text { The best way to reduce your risk of tobacco-related } \\
\text { diseases is to completely quit tobacco use. } \\
\text { HeatSticks contain nicotine, which is addictive. }\end{array}$ & $\begin{array}{l}\text { Important warning: } \dagger \\
\text { It has not been demonstrated that switching to the } \\
\text { iQOS system reduces the risk of developing tobacco- } \\
\text { related diseases compared with smoking cigarettes. } \\
\text { HeatSticks contain nicotine, which is addictive. } \\
\text { Using the iQOS system can harm your health. }\end{array}$ \\
\hline
\end{tabular}

the iQOS system can harm your health.

Source, PMI Research and Development. 6.4 Consumer Understanding and Perceptions. 2015. Available at: https://www.accessdata.fda.gov/Static/widgets/tobacco/MRTP/PMP/ PMP_MRTPA_FDA-2017.zip

*'Available evidence to Date'. Term used by PMI to refer to 'caveats on disease risk and addiction included in PMI Warnings'

†'Important Warning'. Term used to refer to proposed warnings developed by PMI.

In making the determination of whether to issue either a risk modification or an exposure modification order, FDA must take into account the net 'benefit to the health of the population as a whole', considering 'the increased or decreased likelihood that existing users of tobacco products who would otherwise stop using such products will switch to the tobacco product that is the subject of the application' and 'the increased or decreased likelihood that persons who do not use tobacco products will start using the tobacco product that is the subject of the application' (Tobacco Control Act section 911(g)(4)). For an exposure modification order, the applicant must also demonstrate that actual consumer perception tests show that, 'as the applicant proposes to label and market the product, consumers will not be misled into believing that the product - (I) is or has been demonstrated to be less harmful; or (II) presents or has been demonstrated to present less of a risk of disease than one or more other commercially marketed tobacco products' (Tobacco Control Act section 911(g)(2)(B)(iii)).

Therefore, to obtain a risk modification order under US law allowing PMI to market IQOS with its proposed labelling and advertising claims, PMI must present scientific data demonstrating that switching completely from conventional cigarettes to IQOS significantly reduces harm and the risk of tobacco-related diseases. To obtain an exposure modification order allowing PMI to market IQOS with its proposed labelling and advertising claim, PMI must demonstrate that switching completely from cigarettes to IQOS significantly reduces consumers' exposure to harmful substances, and that actual consumer perception studies show that consumers understand that the product has not been demonstrated to be less harmful or present less risk of disease.

The goal of this paper is to critically review the reports on the studies PMI submitted as part of its MRTP application for IQOS to support their proposed marketing claims, with a particular focus on the statements that switching completely to IQOS reduces risk. ${ }^{11}$

\section{METHODS}

Beginning in May 2017, the FDA made most of PMI's MRTP application materials for their HTP available online on a rolling basis for public comment. Most of the materials, including PMI's actual studies, were not publicly available until November 2017. We reviewed and analysed PMI's IQOS MRTP application materials and researched the relevant available literature to evaluate the evidence to support PMI's claims. We reviewed sections in the application that are pertinent to the product advertisements, warning labels and PMI's reports of relevant studies. We examined these application documents to establish what PMI provided as evidence in support of their MRTP application and sought to determine whether such evidence was sufficient. To determine sufficiency, we reviewed study designs, reported study limitations, and determined whether conclusions were supported by the data. Methods used by PMI in their studies are discussed below within the context of the MRTP application claims.

We examined PMI's studies for evidence that tobacco consumers and non-consumers will accurately understand the risks of IQOS as conveyed by PMI's proposed claims and understand what is meant by 'switching completely'; that IQOS claims will not affect combustible tobacco users' intentions to quit; and that combustible tobacco users will completely switch to IQOS (see table 2 for overview of PMI studies).

\section{RESULTS \\ PMI did not provide sufficient evidence of consumer understanding of the concept of switching completely}

PMI conducted quantitative studies to test comprehension of and risk perceptions associated with their proposed modified risk claims (section 6.4). ${ }^{11}$ Table 1 delineates PMI's designated study numbers, PMI's claims and what PMI termed 'available evidence' that were shown to participants. Studies were conducted among US adult consumers ( $n=6774$ total for the three studies), who were stratified into five groups: smokers with no intention to quit, smokers with an intention to quit, former smokers, never smokers and never smokers from the legal smoking age to age 25 years. Participants were then randomised by stratum and exposed to different combinations of PMI proposed claims and warnings or to the current Surgeon General's warnings mandated for cigarettes: (1) 'Smoking causes lung cancer, heart disease, emphysema, and may complicate pregnancy;' (2) 'Quitting smoking now greatly reduces serious risks to your health;' (3) 'Smoking by pregnant women may result in fetal injury, premature birth, and low birth weight;' and (4) 'Cigarette smoke contains carbon monoxide'. Table 3 presents outcome measures used in these studies. 
Table 2 Overview of studies conducted by Philip Morris International (PMI) in support of its MRTP application

\begin{tabular}{|c|c|c|c|}
\hline Study name & Methodology & Study year & Stated study goal \\
\hline $\begin{array}{l}\text { THS-PBA- } \\
01-\text {-US }\end{array}$ & $\begin{array}{l}\text { Qualitative and } \\
\text { quantitative }\end{array}$ & $\begin{array}{l}\text { December } \\
\text { 2012-June } \\
2014\end{array}$ & $\begin{array}{l}\text { Development and validation of } \\
\text { psychometric instruments for 'Risk } \\
\text { Perception' and 'Intent to Use for } \\
\text { tobacco products' }\end{array}$ \\
\hline $\begin{array}{l}\text { THS-PBA- } \\
02-\text { US }\end{array}$ & Qualitative & $\begin{array}{l}\text { October- } \\
\text { December } \\
2013\end{array}$ & $\begin{array}{l}\text { Testing } 9^{*} \text { potential 'plain text' } \uparrow \\
\text { messages }\end{array}$ \\
\hline $\begin{array}{l}\text { THS-PBA- } \\
\text { 03-US }\end{array}$ & Quantitative & $\begin{array}{l}\text { October- } \\
\text { December } \\
2014\end{array}$ & $\begin{array}{l}\text { Testing three potential 'plain text' } \\
\text { messages selected from THS-PBA- } \\
02 \text {-US }\end{array}$ \\
\hline $\begin{array}{l}\text { THS-PBA- } \\
\text { 04-US }\end{array}$ & Qualitative & $\begin{array}{l}\text { December } \\
2014\end{array}$ & $\begin{array}{l}\text { Testing five potential branded } \neq \\
\text { communication materials with } \\
\text { claims selected from THS-PBA-02-US }\end{array}$ \\
\hline $\begin{array}{l}\text { THS-PBA-05- } \\
\text { RRC-US }\end{array}$ & Quantitative & July 2015 & $\begin{array}{l}\text { Testing three branded } \\
\text { communication materials with claim } \\
\# 1 \text { 'Reduced risks of tobacco-related } \\
\text { diseases' }\end{array}$ \\
\hline $\begin{array}{l}\text { THS-PBA-05- } \\
\text { RRC2-US }\end{array}$ & Quantitative & $\begin{array}{l}\text { September } \\
2015\end{array}$ & $\begin{array}{l}\text { Testing three branded } \\
\text { communication materials with the } \\
\text { claim \#2 'Reduced risk of harm' }\end{array}$ \\
\hline $\begin{array}{l}\text { THS-PBA-05- } \\
\text { REC-US }\end{array}$ & Quantitative & $\begin{array}{l}\text { December } \\
2015\end{array}$ & $\begin{array}{l}\text { Testing three branded } \\
\text { communication materials with the } \\
\text { claim \#3 'Reduced body's exposure } \\
\text { to harmful and potentially harmful } \\
\text { chemicals' }\end{array}$ \\
\hline
\end{tabular}

${ }^{*}$ The table in the PMI document mentions 9 messages, but there were actually 13 different messages for phase I because there are two versions of some (A1, A2, B, C1 , C2, D and so on). Phase II of the study tested seven messages.

$\dagger^{\prime}$ Plain text' message describes the information communicated on the product. $\ddagger$ Branded communication materials were brochure, pack, and direct mail piece with the iQOS commercial name and the Tobacco Sticks as HeatSticks with the Marlboro Brand.

MRTP, modified risk tobacco product.

While PMI emphasised that the majority of participants were able to select the 'correct' statement (indicating that the risk of tobacco-related diseases can be reduced by completely switching from cigarettes to IQOS), PMI did not test whether participants understood what 'switching completely' meant. PMI reported that after seeing the proposed claims, $62 \%-78 \%$ of all participants were able to identify the 'correct' statement, which indicated that the risk of tobacco-related diseases can be reduced by completely switching from cigarettes to IQOS. However, this question did not measure whether participants understood the phrase 'completely switching', rather it tested recognition of the terms 'reduced' and 'eliminates'; all response options included the phrase 'completely switch'. Still, PMI interpreted this finding to indicate participants understood the 'reduced' risks of IQOS compared with regular cigarettes. Further, to assess perceptions of their claims and the IQOS product, PMI created and used a new 18-item Perceived Health Risk Scale, a 7-item Perceived Addiction Risk Scale and a 2-item Perceived Harm to Others Scale. PMI reported that HTP was on average ' 8 and 22 points lower than conventional cigarettes on the 0 to 100 perceived health risk scale'. ${ }^{12}$ Hence, PMI failed to demonstrate at least two important factors that FDA deemed critically important to its review of MRTP applications: (1) Whether consumers fully 'understand the modified risk claims and the significance of the information in the context of one's health'. (2) Whether consumers truly understand 'the health risks of using the product.'
PMI's studies of whether smokers will completely switch from cigarettes to IQOS

Premarket human behaviour studies (design and results)

PMI's proposed marketing claims were all contingent on the phrase 'switching completely' from cigarettes. PMI's application drew evidence from two groups of premarket studies in which adult daily cigarette smokers were provided with IQOS HeatSticks and asked to record their tobacco use over time. The 'Whole Offer Test' (WOT) studies were conducted in five countries (Japan, Italy, Germany, Switzerland and South Korea) and the study THS-PBA-07-US took place in USA (table 4).

Participants were instructed to record each instance of using IQOS or smoking a cigarette in an electronic (THS-PBA-07-US) or pencil-and-paper (WOT) diary. The WOT studies ran for 4 weeks; THS-PBA-07-US ran for 6 weeks. Participants were given access to IQOS free of charge and, presumably, purchased any cigarettes at their own expense.

The studies examined several behavioural patterns, based (presumably, but not explicitly) on the percentage of diary entries made for use of a cigarette or IQOS. There was no category for 'switching completely' from cigarettes to IQOS. The 'exclusive' IQOS category included individuals at 95\%-100\% IQOS use, not necessarily completely switched, and not counting tobacco products other than IQOS and cigarettes. Behaviours beyond 6 weeks, when HeatSticks were no longer available for free, were not examined.

In these PMI studies, switching from cigarettes to 'exclusive' (ie, 95\%-100\%) IQOS use was rare (table 5). In THS-PBA-07-US, among adult daily cigarette smokers who completed the 6-week follow-up period, only 6\% (58/968) of participants achieved 'exclusive' IQOS use, defined by PMI as using IQOS $\geq 100$ times during the study and having HeatSticks comprise $\geq 95 \%$ of total recorded amount of cigarettes smoked and HeatSticks used in week 6 (table 4). Only 3\% (15/465) of study completers who also kept valid diaries throughout achieved exclusive use (per-protocol analysis), and among all completers who reported using IQOS $\geq 100$ times, just 16\% become exclusive users. Occurrence of exclusive IQOS use among study completers was similarly uncommon in other settings: Japan (13\%), Italy (5\%), Germany (8\%), Switzerland (4\%) and South Korea (15\%).

\section{Premarket human behaviour studies (limitations)}

The WOT and THS-PBA-07-US studies did not provide sufficient evidence that a substantial portion of adult cigarette smokers will completely switch to IQOS, first and foremost because the outcome 'switching completely' (ie,100\% IQOS use) was not reported. Additional limitations deserve mention. For example, participants were given access to IQOS HeatSticks free of charge but, presumably, purchased cigarettes, giving an economic advantage to IQOS over cigarettes that would not be present in a real world setting.

No efforts to validate the accuracy of the self-reports were described. There was no comparison group to evaluate how keeping a daily tobacco diary, regardless of access to IQOS, would affect cigarette consumption. Such validation is important, as it is well documented that individuals change their behaviour when asked to keep a running log, such as food diaries. ${ }^{13} 14$ Given that approximately half the sample did not use the diaries to document tobacco use for the duration of the study, the validity of estimates based on the full sample is questionable.

PMI reported that the proportion of participants switching back to cigarettes from exclusive IQOS use was 'very low'. However, participants were not classified as switching back to 
Table 3 Outcome measures in quantitative studies

\begin{tabular}{|c|c|c|}
\hline Construct & Instrument & Example questions \\
\hline Intent to use & $\begin{array}{l}\text { The Intent to Use Questionnaire (ITUQ) } \\
\text { Intention to try (ie, to sample at least once; two items) } \\
\text { Intention to use (ie, for continued usage; two items) } \\
\text { (Answers on a 6-point scale from 'Definitely Not' to 'Definitely') }\end{array}$ & $\begin{array}{l}\text { Based on what you know about IQOS, how likely or unlikely are you to try } \\
\text { IQOS? } \\
\text { If you try IQOS and like it, and taking into consideration the prices that } \\
\text { are shown on the material, how likely or unlikely are you to use IQOS } \\
\text { regularly? }\end{array}$ \\
\hline $\begin{array}{l}\text { Change in intention to } \\
\text { quit smoking }\end{array}$ & $\begin{array}{l}\text { Yes/no questions based on Prochaska and DiClemente's Stages of Change } \\
\text { mode }\left.\right|^{31} \text { measured before and after exposure to IQOS message to determine } \\
\text { change in intention to quit smoking (four items- - two for smoking, two for } \\
\text { all tobacco products) }\end{array}$ & $\begin{array}{l}\text { Are you seriously considering quitting smoking within the next } 6 \text { months? } \\
\text { Are you planning to quit smoking in the next } 30 \text { days? }\end{array}$ \\
\hline Comprehension & $\begin{array}{l}\text { 1. 'Global comprehension': overall comprehension of the IQOS message } \\
\text { on exposure to harmful chemicals and risk of tobacco-related diseases } \\
\text { of using IQOS. } \\
\text { 2. 'Specific comprehension': comprehension of three specific parts of the } \\
\text { IQOS message: the Intended Users Statement, Evidence Statement and } \\
\text { Warning Statement. } \\
\text { Both types of comprehension were assessed with multiple-choice questions, } \\
\text { five response options were presented, with one correct option, three } \\
\text { incorrect options and an option for 'don't know'. }\end{array}$ & $\begin{array}{l}\text { Next, thinking about all of the information on the IQOS material, } \\
\text { completely switching from conventional cigarettes to IQOS: } \\
\text { a. Can increase the risk of tobacco-related diseases. } \\
\text { b. Can reduce the risk of tobacco-related diseases (correct). } \\
\text { c. Has the same risk of tobacco-related diseases. } \\
\text { d. Can eliminate the risk of tobacco-related. diseases } \\
\text { e. Don't know. } \\
\text { What happens to tobacco when IQOS is used? } \\
\text { a. It is burned. } \\
\text { b. It remains at room temperature. } \\
\text { c. It is cooled. } \\
\text { d. It is heated but not burned (correct). } \\
\text { e. Don't know. }\end{array}$ \\
\hline Risk perception & $\begin{array}{l}\text { The Perceived Risk Instrument-Personal Risk (PRI-P) comprised of two } \\
\text { domains, each measured by a unidimensional scale: } \\
\text { 1. Perceived Health Risk } 18 \text {-item Scale } \\
\text { 2. Perceived Addiction Risk } 7 \text {-item Scale } \\
\text { 3. Perceived Harm to Others (two separate questions) } \\
\text { Answers were no risk, low risk, moderate risk, high risk, very high risk and } \\
\text { don't know, and were later converted into a } 0 \text { to } 100 \text { scale ( } 0=\text { no risk and } \\
100=\text { very high risk) }\end{array}$ & $\begin{array}{l}\text { If you were to start using IQOS, what do you think would be the risk, if } \\
\text { any, to you personally of getting the following (sometime during your } \\
\text { lifetime) because you use IQOS...losing some sense of taste, having heart } \\
\text { disease, an earlier death, having sores of the mouth or throat, and so on. } \\
\text { If you were to start using IQOS, what do you think would be the risk, if } \\
\text { any, to you personally of experiencing the following because you use } \\
\text { IQOS... being unable to quit cigarettes, feeling like you have to smoke } \\
\text { cigarettes, and so on. } \\
\text { If you were to start using IQOS, what do you think would be the risk, } \\
\text { if any, to others because you use IQOS... harming others through your } \\
\text { secondhand smoke, harming unborn baby. }\end{array}$ \\
\hline
\end{tabular}

Source, Adopted from Table 17 in the Executive Summary, p. $121 .^{15}$

smoking (cigarettes) unless cigarettes comprised $70 \%$ of products used, and participants first had to be classified as 'exclusive' IQOS users, leaving only a fraction of the observation period remaining to switch back. Nonetheless, PMI concluded that IQOS 'has the potential to completely 'switch' a sizeable proportion of participants', ${ }^{15}$ despite the fact that in these PMI studies, an unknown percentage (but no more than 3\%-15\%) of adult cigarette smokers with access to IQOS free of charge switched completely. Together, the potentially misleading and arbitrary product use definitions, non-validated measurement methods, lack of a comparison group, and differential financial cost between IQOS and cigarettes cast doubt on the real world relevance of these PMI behavioural studies, even had the occurrence of switching completely been more common.

\section{PMI summary reports misrepresent their own data on the effects of message exposure on changing intentions to quit smoking}

The executive summary of the MRTP application, referring to the results stated in the executive summary of PMI's MRTP application, reported the effect of the proposed claims on smokers' intentions to quit smoking cigarettes, stating that: 'most smokers did not change their intentions to quit, maintaining positive responses to quitting in a range of $83 \%$ to $97 \%$ across all arms of the study'. However, the study tables showed that PMI designated participants who lowered their intentions to quit from planning to quit in the 'next 30 days' to planning to quit within 'next 6 months' as 'did not change their intentions to quit'. ${ }^{16}$ The disaggregated data show that among those who had intentions to quit in the next 30 days at baseline, between $7 \%$ and 24\% reduced their intentions to 'quit within next 6 months' and an additional 3\%-10\% said they no longer plan to quit. Among those who planned to quit in the next 6 months at baseline, 5\%-17\% indicated they no longer had intentions to quit (see tables 4 and 6 for detailed findings). Similarly, the executive summary for studies THS-PBA-05-RRC, THS-PBA-05-RRC2 and THS-PBA-05-REC stated that smokers with intentions to quit 'did not appreciably change their stated intentions to quit smoking...' and listed proportions of participants who 'stated a change in intentions' between $3.2 \%$ for increased intentions and $11.8 \%$ for decreased intentions. ${ }^{17-19}$ The detailed data in the tables show that among smokers who planned to quit within 30 days, after exposure 3\%-24\% deferred quitting to the next 6 months, and an additional $0 \%-10 \%$ changed to stating they never planned to quit. Further, detailed study results found in PMI results tables show much greater reductions in intentions to quit following exposure to IQOS messaging when compared with the results PMI emphasised in the executive summary.

\section{PMI's perceived risk measures were flawed and incomplete}

PMI's perceived risk instrument was flawed and the choice of their risk perception questions was seemingly guided by tobacco companies' goals rather than measures of validity. ${ }^{8}$ In their Instrument, PMI measured absolute perceptions of risk for each product (separately for cigarettes, e-cigarettes and IQOS; for example, 'If you were to start [smoking/using e-cigarettes/ using IQOS], what do you think would be the risk, if any, to you personally of experiencing the following because you [smoke 
Table 4 Premarket human behaviour studies

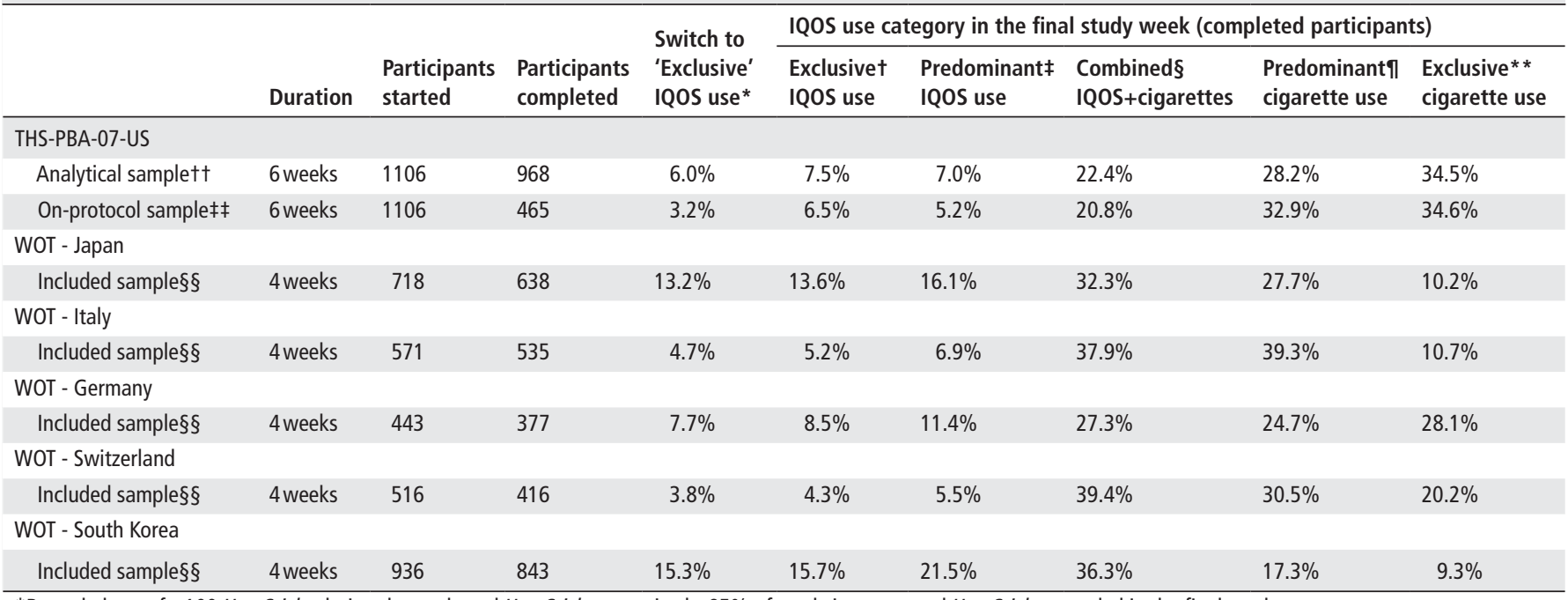

*Recorded use of $\geq 100$ HeatSticks during the study and HeatSticks comprised $\geq 95 \%$ of total cigarettes and HeatSticks recorded in the final week.

tOf cigarettes and HeatSticks recorded, HeatSticks comprised $\geq 95 \%$ of total.

$\ddagger$ Of cigarettes and HeatSticks recorded, HeatSticks comprised $\geq 70 \%$ but $<95 \%$ of the total.

$\S 0$ cigarettes and HeatSticks recorded, HeatSticks comprised $\geq 30 \%$ but $<70 \%$ of the total.

१Of cigarettes and HeatSticks recorded, HeatSticks comprised $\geq 5 \%$ but $<30 \%$ of the total.

${ }^{* *}$ Of cigarettes and HeatSticks recorded, HeatSticks comprised $<5 \%$ of the total.

††Analytical sample restricted to a subset of enrolled participants who met inclusion criteria and recorded $\geq 1$ cigarette use during the 1-week baseline run-in period and $\geq 1$ IQOS HeatStick use during the 6-week observation period (excludes 262 of 1368 initially enrolled participants).

¥¥Per-protocol sample restricted to participants who also documented tobacco use 39 days of the 42-day observation period and did not report IQOS use exceeding number of HeatSticks supplied by $>5 \%$ or 20 units.

$\S \S$ Sample restricted to participants who completed 26 of the 28 daily tobacco use diary entries (ranges from $81 \%$ to $93 \%$ of participants who were eligible to begin the 4 -week studies based on willingness to use IQOS).

n/a=not applicable; nr, not reported; WOT, whole offer test.

cigarettes/use e-cigarettes/use IQOS]...'), rather than asking direct comparative questions (eg, 'Are (IQOS products) less harmful/equally as harmful/more harmful than (cigarettes)?'). A better approach would have been to use both types of questions. Not doing so unavoidably biased results. Further, PMI did not provide any information on how a particularly relevant population-youth—will perceive these claims.

\section{PMI failed to include a control group in studies testing effects of claims and marketing materials}

PMI's designs to assess perceptions and intentions to quit did not include a control group. A control group with no exposure to IQOS information or to marketing material without any modified risk claim but with a strong health-related warning would have allowed PMI to draw conclusions on the effects of the

Table 5 Postexposure intentions to quit among smokers who intend to quit within the next 6 months at baseline

\begin{tabular}{lllll}
\hline Row \# & Study & $\begin{array}{l}\text { Next } \\
6 \text { months }\end{array}$ & No intention & $\begin{array}{l}\text { Increased intentions } \\
\text { to quit (next 30 days) }\end{array}$ \\
\hline 1 & PBA-03 & $79 \%-90 \%$ & $5 \%-17 \%$ & $0 \%-5 \%$ \\
\hline 2 & PBA-05-RRC & $80 \%-89 \%$ & $7 \%-18 \%$ & $0 \%-6 \%$ \\
3 & PBA-05-RRC2 & $74 \%-98 \%$ & $0 \%-21 \%$ & $2 \%-6 \%$ \\
\hline 4 & PBA-05-REC & $76 \%-92 \%$ & $7 \%-19 \%$ & $0 \%-5 \%$ \\
\hline 5 & Overall & $74 \%-98 \%$ & $0 \%-21 \%$ & $0 \%-6 \%$ \\
\hline
\end{tabular}

Note. Showing proportion of respondents among those who originally reported intention to quit within the next 6 months $(100 \%)$ and then chose each answer postexposure to PMI proposed claims. The range indicates the lowest and highest numbers among the different messages/arms used in each study. PMI reports data separately for each arm of the study, rather than presenting the average for the whole study. messages on perceptions of risk of IQOS, and on intent to use and intent to quit smoking. Without a control group it is impossible to tell whether the messages had an effect on intentions to quit, if the effect was a result of repeated testing, or if using messages without modified risk claims may have prevented or otherwise altered the reported reduction in intentions to quit smoking.

\section{DISCUSSION}

We found deficiencies with the evidence provided by PMI in support of their assertions that current smokers will understand what is meant by the phrase 'switching completely'; that IQOS users will not in fact 'switch completely' from smoking cigarettes to using IQOS and may become 'dual users' of IQOS and cigarettes; and that their proposed claims will not decrease smokers' intentions to quit smoking. Further, the studies and measurement instruments employed by PMI suffer from design flaws and their reporting of associated findings is misleading. ${ }^{162} 21$

In their MRTP application, PMI included three proposed claims of reduced harm, risk and exposure that assert 'switching completely' from cigarettes to IQOS bestows health benefits. ${ }^{11}$ According to the Tobacco Control Act section 911(g)(2)(B)(iii), in MRTP applications for exposure modification orders, the applicant is required to demonstrate that consumers will not be misled by claims in labels or advertising. In their MRTP application materials, PMI failed to provide evidence that current smokers will understand what is meant by the phrase 'switching completely'.

PMI did not provide adequate evidence of how and if people understood the phrase 'completely switching', as used in their claims. Instead, their research only tested recognition of the terms 'reduced' versus 'eliminates', because the questionnaire 


\begin{tabular}{llllll}
\hline \multicolumn{2}{l}{ Table 6} & \multicolumn{2}{l}{ Postexposure Intentions to quit among smokers who intend to quit within the next 30 days at baseline } \\
\hline Row \# & Study & Plan to quit in the next 30 days & Plan to quit in the next 6 months & No intention to quit & Total reduction \\
\hline 1 & PBA-03 & $67 \%-90 \%$ & $7 \%-24 \%$ & $3 \%-10 \%$ & $10 \%-33 \%$ \\
2 & PBA-05-RRC & $83 \%-95 \%$ & $3 \%-18 \%$ & $0 \%-3 \%$ & $5 \%-17 \%$ \\
3 & PBA-05-RRC2 & $73 \%-95 \%$ & $3 \%-24 \%$ & $2 \%-6 \%$ & $5 \%-27 \%$ \\
4 & PBA-05-REC & $83 \%-97 \%$ & $3 \%-15 \%$ & $0 \%-7 \%$ & $3 \%-17 \%$ \\
5 & Overall & $67 \%-97 \%$ & $3 \%-24 \%$ & $0 \%-10 \%$ & $3 \%-33 \%$ \\
\hline
\end{tabular}

Note. Showing proportion of respondents among those who originally reported intention to quit within the next 30 days (100\%) and then chose each answer postexposure to PMI proposed claims. The range indicates the lowest and highest number among the different messages/arms used in each study. PMI reports data separately for each arm of the study, rather than presenting the average for the whole study.

asked, after reading the warning labels of IQOS, whether the respondents think 'completely switching from conventional cigarettes to IQOS' results in (1) 'increase the risk of tobacco-related diseases', (2) 'reduce the risk of tobacco-related diseases', (3) 'the same risk of tobacco-related diseases', (4) 'eliminate the risk of tobacco-related diseases' (underlines added). There remains considerable concern that IQOS consumers and potential IQOS consumers will not fully understand there is a contingency to PMI's claim of modified risk—namely, that one must 'completely switch' from cigarettes to IQOS to benefit their health.

PMI also failed to test whether people understood that 'switching completely' refers to switching away from cigarettes; thus, there is concern that e-cigarette users could interpret the claim to mean switching away from any tobacco product, including e-cigarettes, to a HTP would reduce harm, despite there being no evidence that IQOS are less harmful to health than e-cigarettes.

The claim that switching completely to IQOS could reduce harm and tobacco-related diseases assumes that people who attempt to switch will be successful at cigarette smoking cessation. However, available data suggest that cigarette smokers who try to switch from cigarettes to other tobacco products or who use other tobacco products for smoking cessation are more likely to be nicotine-dependent and experience difficulty with smoking cessation compared with people who do not use these alternative tobacco products. ${ }^{22}$ Further, PMI ignores evidence that smokers who use novel tobacco products such as e-cigarettes often use two or more tobacco products in combination instead of switching entirely. Indeed, PMI's own data on IQOS show substantial levels of combined use in their test populations, and epidemiological evidence demonstrates that for other non-cigarette tobacco products, switching completely is not the most common outcome. Among US adults who use electronic cigarettes, $75 \%$ to $82 \%$ use e-cigarettes in combination with at least one other form of combustible tobacco, and only $20 \%$ of e-cigarette users report switching completely from combustible cigarettes. Finally, PMI's proposed warnings do not specifically inform consumers that continuing to smoke while using IQOS could reduce the likelihood of quitting smoking. ${ }^{23}{ }^{24}$ As such, PMI's data do not support their MRTP claim, and instead both data presented by PMI and in the literature base support the idea that introducing any HTP product (including IQOS) will likely be harmful to population health.

Research on e-cigarettes indicates that some dual users of e-cigarettes and combustible cigarettes viewed reduction in smoking as equivalent to quitting, not recognising the need to switch completely. ${ }^{23}$ The evidence base showing adult tobacco users have difficulty understanding modified risk 'warnings' such as 'light' or 'low tar' cigarettes is well known, widely accepted and was relied on in formulating the Tobacco Control Act of 2009. Moreover, such messages are also shown to be misinterpreted by youth. ${ }^{25-27}$ When individuals do not adequately understand warning messages or receive vague messages, they often make assumptions that the tobacco product is safe and are therefore more likely to initiate and/or continue using the product. ${ }^{2628}$ In fact, the Tobacco Control Act, Section 2, Finding 40 states:

The dangers of products sold or distributed as modified risk tobacco products that do not in fact reduce risk are so high that there is a compelling governmental interest in ensuring that statements about modified risk tobacco products are complete, accurate, and relate to the overall disease risk of the product.

PMI's studies failed to offer findings that users and potential users of IQOS will not harbour similar misperceptions as has been seen with e-cigarettes and other tobacco products.

PMI also failed to provide evidence that their proposed claims will not decrease smokers' intentions to quit smoking or that IQOS users will in fact 'switch completely' from smoking cigarettes to using IQOS. ${ }^{15}$ Instead, the evidence provided by PMI showed that use of both cigarettes and IQOS would be the predominant pattern, rather than switching completely from smoking cigarettes to using the IQOS. The detailed reports for PMI's studies on the effect of exposure to their proposed warnings on intentions to quit did not present information separately for smokers who had intentions to quit in the next 30 days and those with intentions to quit in the next 6 months at baseline. Rather, they obfuscated findings that actually showed that postexposure to their proposed warnings, up to nearly a quarter of smokers who planned to quit in the next 30 days at baseline switched to planning to quit within the next 6 months, and up to an additional $10 \%$ no longer intended to quit. Similarly, up to $24 \%$ of smokers who had planned to quit within the next 6 months at baseline said they were never planning to quit postexposure. In multiple instances, PMI's MRTP application departs from standard practices in scientific reporting, leaving out important methodological details, using non-standard, non-validated measurement tools and definitions, and summarising findings in misleading ways. For example, in examining whether non-smokers would be interested in using IQOS, PMI inappropriately characterised data from limited qualitative studies as representative of consumer perceptions. In their Perceived Risk Instrument, PMI measured absolute perceptions of risk for each product (separately for cigarettes, e-cigarettes and IQOS), rather than asking direct comparative questions. Past research has found that when risks are measured for products separately, a greater proportion of people perceive alternative tobacco products as less harmful. ${ }^{29}$ When comparative risk is measured with a direct question, a greater portion of participants respond that alternative tobacco products are equally as harmful as cigarettes. ${ }^{29} 30$ Use of both types of measures is necessary to demonstrate their findings are not simply an artefact of their carefully designed measurement tool. 


\section{CONCLUSION}

PMI failed to demonstrate that the proposed IQOS claims within their MRTP application, and especially statements regarding 'switching completely' (1) Will be interpreted as meaning that the potential health benefits of IQOS are contingent on one completely quitting cigarettes. (2) Will not result in widespread misperceptions that the IQOS product is a harm-free alternative to combustible cigarettes. (3) Will not lead to substantial product appeal (and subsequent use) among youth, non-smoking adults and former smokers. (4) Are consistent with the scientific evidence of actual harm and exposure. (5) Are consistent with how those marketing claims will be interpreted and perceived by potential consumers. (6) Will not mislead consumers, especially adolescents and young adults, about the health risks of IQOS and the relative risks compared with not using any tobacco product. FDA should deny PMI's MRTP application because it does not include sufficient evidence to address these points.

\section{What this paper adds}

- This study is among the first to critically review data submitted by Philip Morris International (PMI) as part of their modified risk tobacco product (MRTP) application to the Food and Drug Administration (FDA).

- PMI's studies did not provide sufficient evidence that heated tobacco products (HTP) users will completely switch from cigarettes to HTP or that consumers understand the proposed claims regarding exposure, harm and 'switching completely'.

- PMI's MRTP application does not satisfy FDA requirements that consumers will not be misled; therefore, HTP should not be allowed to be marketed with reduced risk claims.

Contributors All authors contributed to the literature review, analyses and writing of the paper.

Funding This work was supported by the US National Cancer Institute and Food and Drug Administration Center for Tobacco Products (P50 CA180890, R00 (A187460) and the National Institute of Drug Abuse and Food and Drug Administration Center for Tobacco Products (P50 DA036128).

Disclaimer The content is solely the responsibility of the author and does not necessarily represent the official views of the National Institutes of Health or the FDA. The funding agencies played no role in design and conduct of the study; collection, management, analysis and interpretation of the data; preparation, review, or approval of the manuscript; or decision to submit the manuscript for publication.

Competing interests None declared.

Patient consent Not required.

Provenance and peer review Not commissioned; externally peer reviewed.

Open access This is an open access article distributed in accordance with the Creative Commons Attribution Non Commercial (CC BY-NC 4.0) license, which permits others to distribute, remix, adapt, build upon this work non-commercially, and license their derivative works on different terms, provided the original work is properly cited, appropriate credit is given, any changes made indicated, and the use is non-commercial. See: http://creativecommons.org/licenses/by-nc/4.0/.

\section{REFERENCES}

1 Hendlin YH, Elias J, Ling PM. The pharmaceuticalization of the tobacco industry. Ann Intern Med 2017;167:278-80

2 Auer R, Concha-Lozano N, Jacot-Sadowski I, et al. Heat-not-burn tobacco cigarettes: smoke by any other name. JAMA Intern Med 2017;177:1050-2.

3 Caputi TL. Industry watch: heat-not-burn tobacco products are about to reach their boiling point. Tob Control 2016;26:609-10.

4 Phillip Morris International. Our tobacco heating system iqos: tobacco meets technology. 2017 https://www.pmi.com/smoke-free-products/iqos-our-tobaccoheating-system (accessed 2 Jul 2018).
5 Tabuchi T, Kiyohara K, Hoshino T, et al. Awareness and use of electronic cigarettes and heat-not-burn tobacco products in Japan. Addiction 2016;111:706-13.

6 Phillip Morris International. Science and innovation: Our findings to date. 2018 https://www.pmi.com/science-and-innovation/our-findings-to-date (accessed $2 \mathrm{Ju}$ 2018).

7 BBC Today. Philip morris could move from normal cigarettes. 2018 https://www.bbc co.uk/programmes/p04jhnsw (accessed 2 Jul 2018).

8 Ong EK, Glantz SA. Constructing "sound science" and "good epidemiology": tobacco, lawyers, and public relations firms. Am J Public Health 2001;91:1749-57.

9 Auf R, Trepka MJ, Selim M, et al. E-cigarette marketing exposure and combustible tobacco use among adolescents in the United States. Addict Behav 2018;78:74-9.

10 King AC, Smith LJ, McNamara PJ, et al. Second generation electronic nicotine delivery system vape pen exposure generalizes as a smoking cue. Nicotine Tob Res 2018;20:ntw327-252.

11 Philip Morris S.A. Philip Morris Products S.A. Modified Risk Tobacco Product (Mrtp) Applications. 2016 https://www.fda.gov/downloads/TobaccoProducts/Labeling/Mark etingandAdvertising/UCM560044.pdf

12 Chrea C, Emilien G, Salzberger T, et al. The Perceived Risk Instrument (PRI) to measure perceived risks associated with the use of nicotine and tobacco products. SRNT 2015 21st Annual Meeting: PMIScience, Philip Morris International. 2015 https:// www.pmiscience.com/library/perceived-risk-instrument-pri-measure-perceived-risksassociated-use-nicotine-and-tobacco

13 Livingstone MB, Prentice AM, Strain JJ, et al. Accuracy of weighed dietary records in studies of diet and health. BMJ 1990;300:708-12.

14 Lissner L, Habicht JP, Strupp BJ, et al. Body composition and energy intake: do overweight women overeat and underreport? Am J Clin Nutr 1989:49:320-5.

15 Philip Morris International Management. SA. THS. 2.7 Executive Summary. https:// www.fda.gov/TobaccoProducts/Labeling/MarketingandAdvertising/ucm546281.htm\#E

16 Philip Morris International Management. S.A THS-PBA-03-US, 15.2-Tables. https:// digitalmedia.hhs.gov/tobacco/static/mrtpa/732pba/PBA03.zip

17 Philip Morris International Management. SA. THS-PBA-05-RRC, Quantitative Assessment of THS 2.2 Label, labeling and marketing material with reduced exposure claims. https://digitalmedia.hhs.gov/tobacco/static/mrtpa/732pba/ PBA05REC.zip

18 Philip Morris International Management. SA. THS-PBA-05-RRC2, Study Report: Second Quantitative Assessment of THS 2.2 Label, labeling, and marketing material with reduced risk claims. https://digitalmedia.hhs.gov/tobacco/static/mrtpa/732pba/ PBA05RRC2.zip

19 Philip Morris International Management. SA. THS-PBA-05-REC, Quantitative assessment of THS 2.2 Label, labeling and marketing material with reduced exposure claims. https://digitalmedia.hhs.gov/tobacco/static/mrtpa/732pba/ PBA05REC.zip

20 Messer K, Vijayaraghavan M, White MM, et al. Cigarette smoking cessation attempts among current US smokers who also use smokeless tobacco. Addict Behav 2015:51:113-9.

21 Shi Y, Pierce JP, White M, et al. E-cigarette use and smoking reduction or cessation in the 2010/2011 TUS-CPS longitudinal cohort. BMC Public Health 2016;16:1105.

22 Zawertailo L, Pavlov D, Ivanova A, et al. Concurrent E-cigarette use during tobacco dependence treatment in primary care settings: association with smoking cessation at three and six months. Nicotine Tob Res 2017:19:183-9.

23 Robertson L, Hoek J, Blank M-L, et al. Dual use of electronic nicotine delivery systems (ENDS) and smoked tobacco: a qualitative analysis. Tob Control 2018. doi: tobaccocontrol-2017-054070. [Epub ahead of print].

24 Tomar SL, Alpert HR, Connolly GN. Patterns of dual use of cigarettes and smokeless tobacco among US males: findings from national surveys. Tob Control 2010;19:104-9.

25 Byron MJ, Baig SA, Moracco KE, et al. Adolescents' and adults' perceptions of 'natural', 'organic' and 'additive-free' cigarettes, and the required disclaimers. Tob Control 2016:25:517-20.

26 Kropp RY, Michels T, Halpern-Felsher B. Adolescents' beliefs about the risks involved in smoking light cigarettes. American Public Health Association Annual Meeting: San Francisco, CA, 2003

27 Peebles K, Hall MG, Pepper JK, et al. Adolescents' responses to pictorial warnings on their parents' cigarette packs. J Adolesc Health 2016;59:635-41.

28 Pepper JK, Emery SL, Ribisl KM, et al. How risky is it to use e-cigarettes? Smokers' beliefs about their health risks from using novel and traditional tobacco products. J Behav Med 2015;38:318-26.

29 Popova L, Ling PM. Perceptions of relative risk of snus and cigarettes among US smokers. Am J Public Health 2013;103:e21-e23.

30 Wackowski OA, Bover Manderski MT, Delnevo CD. Comparison of direct and indirect measures of e-cigarette risk perceptions. Tob Regul Sci 2016;2:38-43.

31 DiClemente CC, Prochaska JO. Self-change and therapy change of smoking behavior: a comparison of processes of change in cessation and maintenance. Addict Behav 1982;7:133-42. 